\title{
PERAN MOTIVASI BELAJAR SEBAGAI VARIABEL MEDIATOR GROWTH MINDSET DAN PARENTING STYLE TERHADAP ACADEMIC GRIT SISWA SMP
}

\section{Faatihatul Ghaybiyyah}

Fakultas Psikologi Universitas Islam Negeri Syarif Hidayatullah Jakarta, Indonesia

Email: haniffa.aulia@gmail.com

\begin{abstract}
Abstrak
Pendidikan merupakan kunci dari berbagai aspek kehidupan, dengan hal ini peneliti melakukan penelitian tentang variabel mediator growth mindset dan parenting style. Penelitian ini bertujuan untuk mengetahui peran motivasi belajar sebagai variabel mediator growth mindset dan parenting style terhadap academic grit siswa SMP. Populasi penelitian ini merupakan seluruh siswa-siswi di SMP Islamiyah Ciputat. Sampel penelitian ini berjumlah 267 siswa dan pengambilan sampel dilakukan secara non-probabality sampling dengan teknik purposive sampling. Peneliti menggunakan alat ukur academic grit yang dikembangkan oleh Clarck dan Malecky, growth mindset menggunakan alat ukur yang dikembangkan oleh Blackwell, Trzesniewski, dan Dweck, parenting style menggunakan alat ukur yang dikembangkan oleh Dunn, dan motivasi belajar menggunakan alat ukur yang dikembangkan oleh Pintrich dan Groot. Analisis data yang digunakan dalam penelitian ini dengan teknik statistik structural equating modeling menggunakan AMOS dan untuk menguji validitas konstruk menggunakan LISREL 8.7. Data penelitian ini dianalisis dengan teknik statistik structural equation modeling dan menghasilkan kesimpulan bahwa ada pengaruh yang signifikan growth mindset terhadap academic grit, tidak ada pengaruh yang signifikan pola asuh authoritative jika dibandingkan authoritarian sebagai kontrol terhadap academic grit, dan tidak ada pengaruh yang signifikan pola asuh permissive jika dibandingkan authoritarian sebagai kontrol terhadap academic grit. Hasil uji model struktural dengan motivasi belajar sebagai variabel mediator menunjukkan bahwa motivasi belajar memiliki pengaruh yang signifikan dalam memediasi pengaruh growth mindset dan parenting style terhadap academic grit. Saran untuk penelitian selanjutnya agar memperbanyak variabel psikologis lainnya agar memperoleh hasil yang lebih komprehensif terkait academic grit.
\end{abstract}

Kata kunci: grit akademik; pola pikir pertumbuhan; gaya pengasuhan; motivasi belajar

\section{Abstract}

Education is key to various aspects of life, with this research conducting research on the mediator variables of growth mindseat and parenting style. This research aims to find out the role of learning motivation as a mediator variable growth mindset and parenting style towards academic grit of junior high school students. The population of this study is all students in SMP Islamiyah Ciputat. The study

$\begin{array}{ll}\text { How to cite: } & \text { G. Faatihatul., (2021) Peran Motivasi Belajar Sebagai Variabel Mediator Growth Mindset dan Parenting } \\ & \text { Style Terhadap Academic Grit Siswa SMP, Syntax Idea, 3(10), https://doi.org/10.36418/syntax- } \\ & \text { idea.v3i10.1510 } \\ \text { E-ISSN: } & \text { 2684-883X } \\ \text { Published by: } & \text { Ridwan Institute }\end{array}$


sampled 267 students and the sampling was conducted on a non-probabality sampling basis with purposive sampling techniques. Researchers used academic grit measuring tools developed by Clarck and Malecky, growth mindset using measuring tools developed by Blackwell, Trzesniewski, and Dweck, parenting style using measuring tools developed by Dunn, and learning motivation using measuring tools developed by Pintrich and Groot. The data analysis used in this study with structural equating modeling statistical techniques used AMOS and to test the validity of constructs using LISREL 8.7. The study data was analyzed with statistical structural equation modeling techniques and resulted in the conclusion that there was a significant influence of growth mindset on academic grit, no significant influence on authoritative parenting when compared to authoritarian as control over academic grit, and no significant influence of permissive parenting when compared to authoritarian as control over academic grit. The results of structural model tests with learning motivation as mediator variables showed that learning motivation had a significant influence in mediating the influence of growth mindset and parenting style on academic grit. Advice for further research to multiply other psychological variables in order to obtain more comprehensive results related to academic grit.

Keywords: academic grit; growth mindset; parenting style

\section{Received: 2021-09-22; Accepted: 2021-10-05; Published: 2021-10-20}

\section{Pendahuluan}

Academic grit menjadi kajian yang menarik untuk diteliti karena merupakan salah satu non-cognitif skills terbaru pada bidang pendidikan. Kajian ini menarik mengingat di Indonesia keterampilan non-kognitif belum maksimal diterapkan kepada siswa. academic grit pada siswa SMP masih tergolong rendah, lebih mudah menyerah ketika nilai kurang memuaskan (Husna \& Satria, 2019) dan kurang fokus dalam mencapai pendidikan (Nuraini \& Aqila, 2020). Siswa putus sekolah karena kurangnya tekad yang kuat (Erawati, 2011), (Deriana, 2019), (Haryanto et al., 2019). Sebelum mengkaji academic grit lebih dalam, alangkah baiknya kita mengerti definisi dari non-cognitive skills itu sendiri.

Menurut (Zhou, 2016) mengutarakan bahwa keterampilan (skills) dianggap sebagai elemen kunci yang berkontribusi pada pembangunan berkelanjutan bangsa dan kesejahteraan individu. Pandangan psikologi terhadap skills difokuskan pada generasi dan fungsi kompetensi apakah seseorang dapat melakukann beberapa tugas. (Zhou, 2016) menambahkan bahwa kemampuan (skills) terbagi menjadi dua, yakni cognitive dan non-cognitive skills. Keterampilan kognitif (cognitive skills) melibatkan kemampuan untuk memahami ide-ide kompleks, untuk beradaptasi secara efektif dengan lingkungan, untuk belajar dari pengalaman, untuk terlibat dalam berbagai bentuk penalaran, dan untuk mengatasi hambatan dengan mengacu pada pemikiran (Pierre et al., 2014).

Cognitive skills mencakup pada kemampuan mental yang digunakan untuk aktivitas berpikir, diantaranya adalah membaca, menulis, dan berpikir (Green, 2011). 
Peran Motivasi Belajar sebagai variabel mediator growth mindset dan parenting style

Berbeda dengan cognitive skills (keterampilan kognitif), non-cognitive skills (keterampilan non-kognitif) merupakan pola pemikiran, perasaan, dan perilaku yang ditentukan secara sosial dan dapat dikembangkan sepanjang hidup untuk menghasilkan nilai (Borghans et al., 2008). Keterampilan non-kognitif terdiri dari sifat-sifat pribadi, sikap, dan motivasi (Zhou, 2016). Non-cognitive skills bisa dikelompokkan menjadi dua bagian yakni, intrapersonal skills (keterampilan intrapersonal) dan interpersonal skills (keterampilan interpersonal). Intrapersonal skills mencakup motivation (motivasi), resilience (resiliensi), time management (managemen waktu), self control (kontrol diri), self efficacy (efikasi diri), optimism (optimisme), dan emotional stability (stabilisasi emosi). Sedangkan interpersonal skills mencakup teamwork (kerja tim), communication (komunikasi), negotiation (negosiasi), dan relationship building (pembangunan relasi).

Keterampilan non-kognitif telah diteliti oleh para peneliti dalam bidang pendidikan, diantaranya adalah motivasi (Vallerand et al., 1992), (Barron et al., 2017), (Wigfield \& Eccles, 2000). Pada hasil penelitian sebelumnya, motivasi mempunyai peran yang sangat penting untuk meningkatkan prestasi akademik siswa, baik siswa SD, SMP, maupun SMA. Keterampilan non-kognitif selanjutnya yakni resilience (Toland, 2011), (Dent \& Cameron, 2003), (Gibbs \& Miller, 2014). Tidak jauh berbeda dengan motivasi, resiliensi juga sangat penting dalam dunia pendidikan. Penelitian sebelumnya menyatakan bahwa resiliensi mampu mengatasi keadaan yang sulit bagi siswa.

Penelitian mengenai keterampilan non-kognitif yang telah dikaji dalam bidang pendidikan yaitu grit juga telah dikaji oleh bberapa penelitian terdahulu yaitu (Reed \& Jeremiah, 2017), (Reraki et al., 2015), (Cross, 2014), (Haktanir et al., 2016), (Levy \& Steele, 2011), (Collaco, 2018), (Coates, 2017), (Stauffer, 2018), (Mitchum, 2018), (Barrington, 2017), (Bowen, 2018). Keterampilan non-kognitif ini menjadi sangat penting untuk dimiliki siswa. Penelitian sebelumnya menyatakan bahwa dengan keterampilan ini, siswa mampu lebih gigih dan semangat untuk mencapai tujuan jangka panjangnya (A. L. Duckworth, 2006), (Suzuki, 2015), (Reed \& Jeremiah, 2017), (Maddi et al., 2017).

Pada penelitian ini, peneliti tertarik untuk mengambil satu konstruk non-cognitive skills sebagai dependent variable, yakni academic grit yang dikembangkan oleh (Clark \& Malecki, 2019). Academic grit merupakan karakteristik individu atau keterampilan yang mencakup tekad, ketahanan, dan fokus dalam mengejar tujuan jangka panjang yang menantang dalam bidang pendidikan (Clark \& Malecki, 2019). Konstruk ini merupakan pengembangan dari konstruk grit yang dicetuskan oleh (Reed \& Jeremiah, 2017). Grit merupakan kegigihan dan semangat untuk mencapai tujuan jangka panjang (Reed \& Jeremiah, 2017). Individu dengan grit yang tinggi akan lebih tekun dalam bekerja, tidak mudah menyerah jika mengalami kegagalan, bahkan dapat menjadikan kegagalan sebagai cambuk untuk semakin berusaha mencapai tujuan (Suzuki, 2015).

Grit mempunyai kemiripan dengan beberapa konstruk psikologi, diantaranya adalah hardiness (sifat tahan banting), resilience (resiliensi), need for achievement (kebutuhan untuk berprestasi), dan adversity quotient. (Maddi, 2006) mendefinisikan hardiness sebagai kombinasi dari sikap yang memberikan keberanian dan motivasi 
untuk melakukan kerja keras dan strategis dalam mengubah keadaan stres dari potensi bencana menjadi peluang pertumbuhan. Berbeda dengan grit yang pada dasarnya merupakan kemampuan individu untuk bertahan memperoleh tujuan tertentu selama periode waktu yang diperpanjang (Reed \& Jeremiah, 2017), hardiness mengacu pada kemampuan individu untuk bertahan melalui keadaan sulit dan tidak mengacu pada kegigihan terhadap tujuan tertentu.

Menurut (Luthar et al., 1993) menyatakan bahwa resiliensi merupakan proses di mana seorang individu mengatasi kesulitan yang signifikan, biasanya dalam bentuk peristiwa yang mengubah kehidupan atau keadaan pribadi yang sulit. Perbedaan yang paling mendasar adalah grit dikonseptualisasikan sebagai sifat, sementara resiliensi adalah proses yang dinamis. Selain hardiness dan resilience, konstruk lain yang mempunyai kemiripan dengan grit adalah need for achievement. Need for achievement merupakan dorongan untuk menyelesaikan tujuan yang dapat dikelola dan memungkinkan individu untuk menerima umpan balik secara langsung (McClelland, 1961). Jika need for achievement membutuhkan umpan balik, grit tidak mengharuskan individu untuk menerima umpan balik.

Konstruk terakhir yang mempunyai kemiripan dengan grit adalah adversity quotient. Menurut (Putri, 2015), adversity quotient merupakan kemampuan seseorang untuk menghadapi masalah. Definisi lain tentang adversity quotient juga dikemukakan oleh (Stoltz, 2005) yakni, kecerdasan seseorang dalam menghadapi rintangan hidup sehari-hari seraya tetap berpegang teguh pada prinsip dan impian tanpa mempedulikan apa yang terjadi. Berbeda dengan grit yang merupakan trait (sifat), adversity quotient merupakan kecerdasan. Grit mempunyai dua aspek penting, yakni concistency of interest dan perseverance of effort (Reed \& Jeremiah, 2017). Kedua aspek tersebut telah dikembangkan dalam ranah pendidikan oleh (Clark \& Malecki, 2019) menjadi academic grit. Pengembangan grit menjadi academic grit mempunyai tiga aspek penting, yakni determination, resilience, dan focus.

Keterampilan non-kognitif ini telah terbukti pada PISA 2015 yang menjadikan Singapura meraih poin tertinggi (Brian, 2015). Indonesia meraih angka 403 pada PISA 2015 untuk pencapaian skor sains. Pencapaian ini lebih baik dibandingkan dengan hasil PISA pada tahun 2012 dengan angka 382 poin. Siswa di Indonesia yang berada di sekolah negeri mempunyai 16 poin lebih tinggi dibandingkan dengan siswa yang berada di sekolah swasta (Kemendikbud, 2016).

Untuk mencapai tujuannya, siswa harus tekun, gigih, mengerti apa yang menjadi tujuan hidupnya dan mampu menghadapi tekanan (Haktanir et al., 2016), (Clark \& Malecki, 2019). Dalam mencapai academic grit yang tinggi, ada dua faktor yang mempengaruhi, yakni faktor internal dan faktor eksternal. Faktor internal diantaranya adalah hope (A. Duckworth, 2016), motivasi belajar (Zhao et al., 2017), growth mindset (Zhao et al., 2017), motivasi (Reraki et al., 2015), academic locus of control (Çelik \& Sariçam, 2018). Sedangkan factor eksternal adalah parenting style (Dunn, 2017), a culture of grit (Çelik \& Sariçam, 2018), dan the playing fields of grit (Çelik \& Sariçam, 2018). 
Pada penelitian ini, peneliti tertarik untuk mengambil growth mindset dan motivasi belajar sebagai faktor internal serta parenting style sebagai faktor eksternal yang mempengaruhi grit. Penelitian sebelumnya yang dilakukan oleh (Zhao et al., 2017) menyatakan bahwa motivasi belajar memediasi growth mindset terhadap grit yang dilakukan pada siswa sekolah dasar dan siswa sekolah menengah pertama di China. Pada penelitian ini, peneliti tertarik untuk menguji model serupa dengan menggunakan konstruk terbaru grit dalam ranah pendidikan, yakni academic grit serta menambahkan faktor eksternal yakni parenting style kepada siswa di Indonesia. Mengapa parenting style? Dalam hasil penelitiannya, (Çelik \& Sariçam, 2018) mengemukakan pentingnya peran orangtua dalam mendukung kegigihan dan semangat jangka panjang putra-putrinya.

Gaya pengasuhan mempunyai tiga tipe, yakni authoritative, authoritarian, dan permissive (Baumrind, 1991). Penelitian sebelumnya menyatakan bahwa tipe pola asuh authoritative mempunyai pengaruh paling besar terhadap academic grit (Dunn, 2017), (Riley et al., 2017), (Dunn, 2017), (Howard et al., 2019). Dikarenakan tipe pola asuh merupakan variabel kategorik, peneliti mengambil satu tipe pola asuh sebagai kontrol, yakni pola asuh authoritarian. Sehingga dalam penelitian ini, ada dua tipe pola asuh yakni, pola asuh authoritative jika dibandingkan dengan authoritarian sebagai kontrol dan pola asuh permissive jika dibandingkan dengan authoritarian sebagai kontrol.

Pada penelitian ini, authoritarian dijadikan sebagai kontrol karena merupakan bagian dari kedua parenting style yang ada, yakni authoritative dan permissive. Authoritative merupakan gaya pengasuhan yang cenderung menuntut dan responsif, authoritarian merupakan gaya pengasuhan yang cenderung menuntut dan mengarahkan, tetapi tidak responsif, sementara permissive merupakan gaya pengasuhan yang direktif lebih responsif daripada yang mereka tuntut (Baumrind, 1991).

Penelitian lain tentang growth mindset dan grit dengan subjek mahasiswa dilakukan oleh (Chrisantiana \& Sembiring, 2017) yang menyatakan bahwa mahasiswa yang memiliki growth mindset mendorong berkembangnya grit ke arah yang lebih tinggi. Penelitian ini juga sebanding dengan penelitian yang dilakukan oleh (Wahidah \& Royanto, 2019) yang menyatakan bahwa growth mindset memprediksi tingkat grit yang lebih tinggi.

Selain itu, penelitian tentang pengaruh motivasi terhadap grit telah banyak dilakukan, diantaranya adalah motivasi akademik (Rojas, 2015), motivasi belajar (Zhao et al., 2017), strategi belajar (Weisskirch, 2018), dan motivasi secara umum (Reraki et al., 2015), (Von Culin et al., 2014). Dalam penelitian ini, peneliti memilih motivasi belajar sebagai mediator karena ingin mengetahui indirect effect (efek tidak langsung) growth mindset dan parenting style terhadap academic grit. Seperti yang telah dilakukan oleh (Zhao et al., 2017) bahwa motivasi belajar memediasi growth mindset terhadap grit.

Berdasarkan data dan fenomena yang telah dijabarkan, memberi gambaran kepada peneliti bahwasanya grit merupakan variabel yang sangat penting dan menarik untuk diteliti. Dalam penelitian ini, peneliti akan mengkaji secara komprehensif faktor internal 
yang mempengaruhi academic grit, yakni growth mindset dan motivasi belajar. Selain faktor internal, peneliti juga ingin menambahkan faktor eksternal, yakni parenting style (tipe pola asuh authoritative dan permissive, authoritarian sebagai kontrol). Sehingga peneliti mengambil judul "Peran Motivasi Belajar sebagai Variabel Mediator Growth Mindset dan Parenting Style terhadap Academic Grit"

\section{Metode Penelitian}

\section{Populasi, Sampel dan Teknik Pengambilan Sampel}

Populasi yang akan diteliti adalah siswa SMP Islamiyah Ciputat. Pada penelitian ini, peneliti menjadikan 267 sampel dari jumlah anggota populasi. Teknik pengambilan sampel dalam penelitian ini dilakukan secara nonprobability sampling yaitu, suatu teknik sampling yang tidak semua populasi mempunyai kesempatan sama untuk bisa dipilih menjadi sampel. Teknik yang digunakan Convenience Sampling yaitu, seseorang diambil sebagai sampel sepanjang dia memenuhi kriteria yaitu siswa SMP Islamiyah Ciputat. Selain itu, peneliti pernah melakukan wawancara dengan siswa di sana dan mendapatkan hasil wawancara bahwa academic grit siswa di SMP Islamiyah Ciputat rendah.

\section{Variabel dan Definisi Operasional}

\section{1) Variabel Penelitian}

Variabel dalam penelitian ini adalah academic grit, growth mindset, parenting style, dan motivasi belajar. Academic grit dijadikan sebagai dependent variable (DV), sedangkan growth mindset dan parenting style dijadikan sebagai independent variable (IV) serta motivasi belajar dijadikan sebagai variabel mediator.

\section{2) Definisi Operasional Variabel Penelitian}

Adapun definisi opersional masing-masing variabel adalah:

a. Academic grit yang dimaksudkan dalam penelitian ini adalah sifat siswa yang mempunyai tekad, ketahanan, dan fokus dalam mengejar tujuan jangka panjang yang menantang dalam bidang pendidikan, yang akan diukur menggunakan skala Academic Grit Scale (Clark \& Malecki, 2019) ditambah dengan mengkonstruksi 5 aitem sebagai tambahan.

b. Growth mindset yang dimaksudkan dalam penelitian ini adalah keyakinan bahwa kecerdasan dapat dikembangkan dan bahwa siswa dapat menumbuhkan kecerdasan mereka untuk mencapai tujuan melalui kerja keras dan dedikasi, yang akan diukur menggunakan skala Implicit Theories of Intelligence Scale for Children (Hibel et al., 2007).

c. Parenting style yang dimaksudkan dalam penelitian ini adalah serangkaian sikap yang ditunjukkan orang tua kepada anak untuk menciptakan iklim emosi yang melingkupi interaksi orangtua-anak, yang akan diukur menggunakan skala Parent Authority Questionnaire Modernized (Dunn, 2017). Dikarenakan gaya pengasuhan merupakan variabel kategorik, peneliti mengambil satu tipe pola asuh sebagai kontrol dengan melakukan dummy coding lalu menjadi dua 
tipe pola asuh, sehingga dapat dituliskan pola asuh authoritative jika dibandingkan dengan authoritarian sebagai kontrol dan pola asuh permissive jika dibandingkan dengan authoritarian sebagai kontrol.

d. Motivasi belajar merupakan sebuah dorongan dan strategi belajar pengaturan diri yang membuat siswa berusaha untuk mendapatkan hasil yang maksimal dalam 40 bidang pendidikan (Pintrich \& De Groot, 1990), yang akan diukur menggunakan skala Motivated Strategies for Learning Questionnaire (MSLQ) yang dikembangkan oleh (Pintrich \& De Groot, 1990).

\section{3) Teknik Pengumpulan Data}

Dalam penelitian ini, teknik pengumpulan data menggunakan skala sebagai alat pengumpul data. Skala adalah sejumlah pernyataan tertulis untuk memperoleh jawaban dari subjek. Skala yang digunakan adalah model skala Likert, yaitu pernyataan pendapat yang disajikan kepada subjek yang memberikan indikasi pernyataan setuju atau tidak setuju.

Jawaban dari setiap item instrumen ini memiliki rentang dari tertinggi (sangat positif) sampai terendah (sangat negatif). Tiap item diukur melalui empat kategori jawaban. Untuk skala academic grit dan learning motivation menggunakan empat kategori yaitu "Sangat Sesuai (SS)", "Sesuai (S)", "Tidak Sesuai (TS)", "Sangat Tidak Sesuai (STS)". Skala growth mindset dan parenting style menggunakan empat kategori yang berbeda yaitu "Sangat Setuju (SS)", "Setuju (S)", "Tidak Setuju (TS)", "Sangat Tidak Setuju (STS)". Hal ini dilakukan untuk menghindari terjadinya pemusatan (central tendency) atau menghindari jumlah respon yang bersifat netral.

Instrumen pengumpulan data ini terdiri dari pernyataan positif (favorable) dan pernyataan negatif (unfavorable). Skor tertinggi diberikan pada pilihan jawaban sangat sesuai atau sangat setuju dan skor terendah diberikan pada pilihan jawaban sangat tidak sesuai atau sangat tidak setuju untuk pernyataan favorable dan begitu pula sebaliknya.

\section{Hasil dan Pembahasan}

\section{A. Hasil Analisis}

\section{Uji Model Pengukuran}

Langkah pertama peneliti membuat sebuah model yang sesuai dengan hipotesis awal sebagai dasar pembuatan kerangka analisis penelitian. 


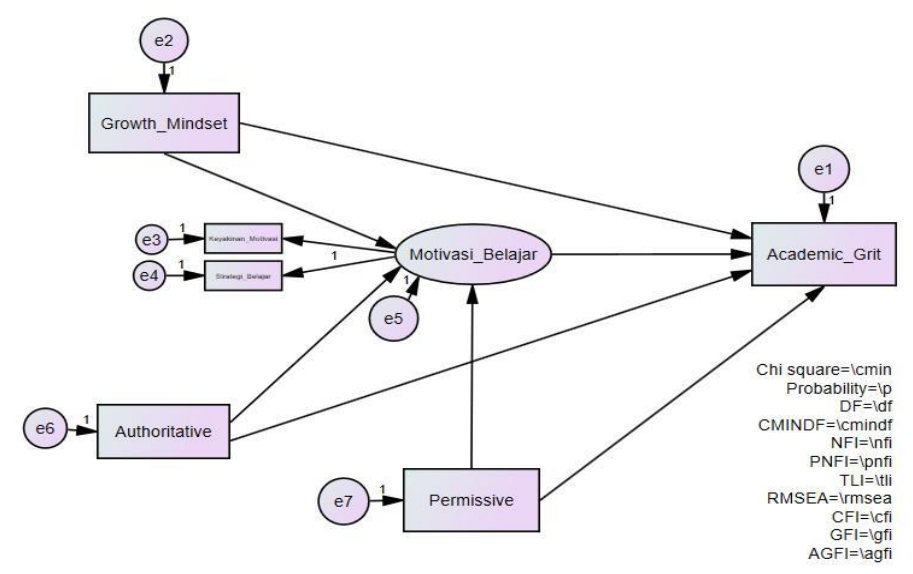

Gambar 1

\section{Path Diagram Model Awal}

Peneliti melakukan pengujian apakah kerangka yang dibuat sudah fit sesuai dengan alur dan menyesuaikannya dengan data. Peneliti membuat model sebagaiamana berikut:

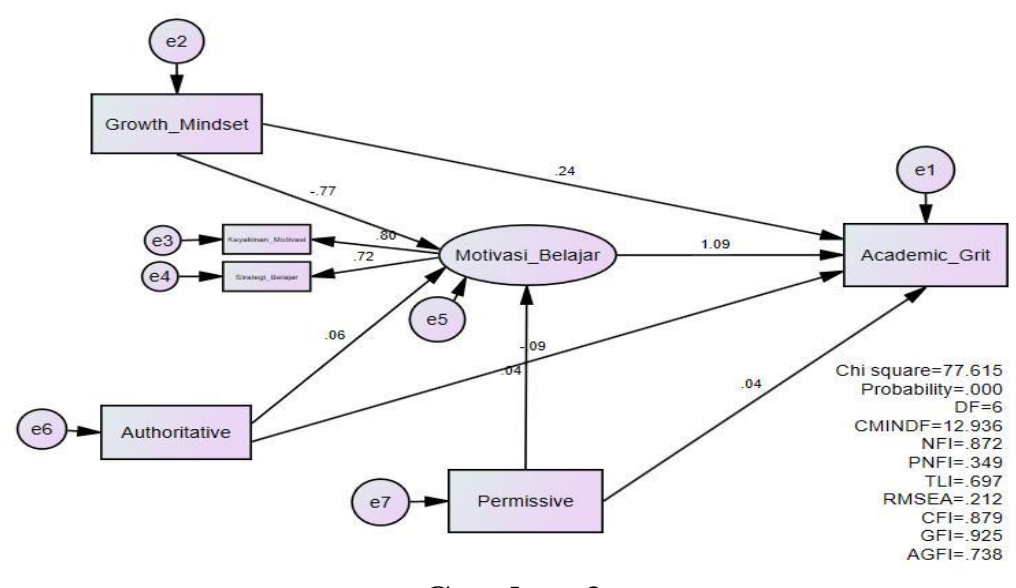

Gambar 2

Hasil Uji Model Pengukuran Awal

Dari gambar di atas diperoleh hasil uji model pengukuran yang didefiniskan dengan nilai chi-squares yang menunjukkan nilai 77.615 dengan CMIN/df $=12.936$. RMSEA $=0.212$ yaitu nilai RMSEA masih belum $<0,05$ dan nilai probabilitas $=0.000$, yaitu nilai tersebut masih lebih kecil dari 0.05, serta nilai AGFI, GFI dan TLI masih <0.09, maka dapat diartikan bahwa model penelitian belum fit dengan data. Berdasarkan dari pengujian model awal tersebut, maka peneliti melakukan modifikasi terhadap model dengan cara menghubungkan antar eror yang bernilai besar, yaitu e6- e7 dan e2-e7. Model digambarkan sebagai berikut: 


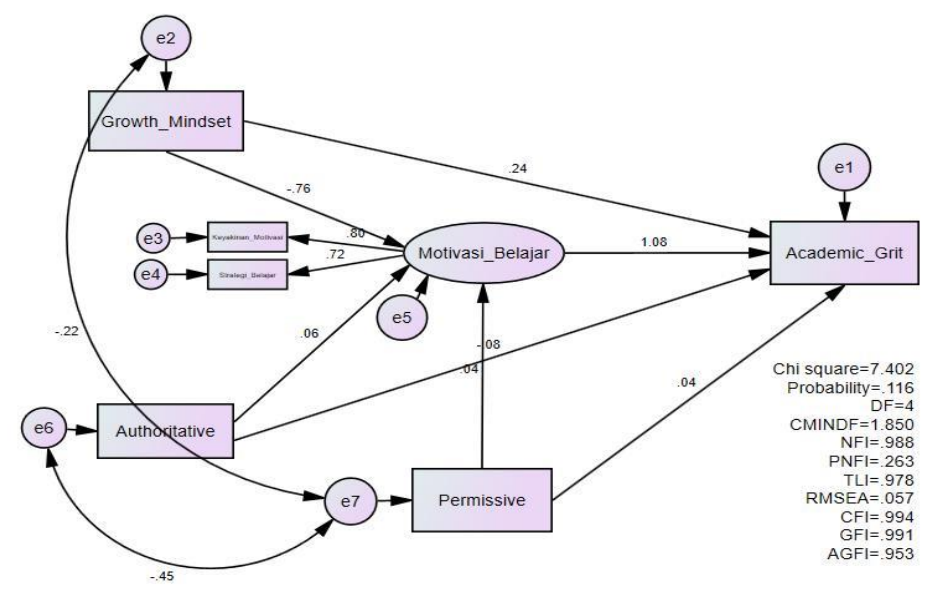

\section{Gambar 3 \\ Hasil Uji Model Setelah Dimodifikasi}

Berdasarkan gambar hasil uji dan dari tabel di atas dapat ditunjukkan kesimpulan bahwa nilai chi-squares menunjukkan nilai 7.402, nilai yang lebih kecil dari sebelum dimodifikasi yaitu 77.615, begitu juga dengan nilai CMIN/df yang semula 12.936 menjadi 1.850 . Nilai probabilitas 0.166 yang berarti $>0.05$, maka dapat diartikan bahwa model penelitian sudah goodness of fit, didukung oleh nilai GFI 0.991, AGFI 0.953, TLI 0.978, dan RMSEA 0.57. Proses modifikasi menghasilkan beberapa nilai eror yang saling bersinggungan, sehingga nilai tersebut dihubungkan untuk melihat nilai hubungan dan keterkaitan satu sama lain. Nilai-nilai dari model yang telah fit dapat dilihat pada tabel 1 di bawah ini

\section{Tabel 1}

Hasil model fit berdasarkan kriteria (GOF)

\section{Kriteria Model Fit}

- $\quad$ Probability $=>0.05$

- RMSEA (Root Mean Square Error of Approximation $)=<0.08$

- GFI (Goodness of Fit Index $)=>0.9$ AGFI (Adjusted Goodness Fit Index) $=>0.9$

- $\quad$ TLI $($ Tucker Lewis Index $)=>0.9$

\section{Data Model Fit}

- Probability $=0.166$

- RMSEA (Root Mean Square Error of Approximation $)=0.36$

- GFI (Goodness of Fit Index $)=>0.991$ AGFI (Adjusted Goodness Fit Index) = $>0.953$

- $\quad$ TLI $($ Tucker Lewis Index $)=>0.978$

\section{1) Uji Model Struktural}

Uji model struktural yang dilakukan berdasarkan skema yang telah disusun dalam kerangka teori. Hasil tersebut dapat dilihat pada tabel 2 


\section{Tabel 2}

Estimate Regresion Weight

\begin{tabular}{llrrr}
\hline Academic Grit & $<-$ Growth Mindset & 0.239 & 2.009 & 0.045 \\
\hline Academic Grit & <- Authoritative & -1.710 & -1.616 & 0.106 \\
\hline Academic Grit & <- Permissive & 0.984 & 1.330 & 0.740 \\
\hline
\end{tabular}

Tabel 3 menunjukkan bahwa estimasi bobot regresi ditemukan hasil uji model struktural. Berikut adalah rincian hasil uji model struktural dengan dua keterangan.

1. Growth mindset memiliki pengaruh yang signifikan terhadap academic grit. Hasil dari pengolahan menunjukkan nilai C.R. (Critical Ratio) sebesar $2.009>$ t-table 1.96 dan dengan nilai $\mathrm{P}<0.05$ yang mempunyai arti bahwa terdapat pengaruh yang signifikan growth mindset terhadap academic grit. Kemudian untuk hasil koefisien estimate sebesar 0.239, hal ini menunjukkan bahwa adanya pengaruh positif antara growth mindset dan academic grit. Maka, semakin tinggi growth mindset akan semakin tinggi academic grit.

2. Pola asuh authoritative jika dibandingkan authoritarian sebagai kontrol tidak memiliki pengaruh yang signifikan terhadap academic grit. Hasil dari pengolahan menunjukkan nilai C.R. (Critical Ratio) sebesar -1.616 < t-table 1.96 dan nilai $\mathrm{P}>0.05$, artinya bahwa tidak terdapat pengaruh yang signifikan pola asuh authoritarian dan academic grit.

3. Pola permissive jika dibandingkan authoritarian sebagai kontrol memiliki pengaruh yang signifikan terhadap academic grit. Hasil dari pengolahan menunjukkan nilai C.R. (Critical Ratio) sebesar $1.330>$ t-table 1.96 dan nilai $\mathrm{P}>0.05$, artinya bahwa tidak terdapat pengaruh yang signifikan pola asuh permissive dan academic grit.

\section{2) Uji Model Struktural dengan Variabel Mediator}

Peneliti melakukan uji model struktural yang dilakukan berdasarkan skema yang telah disusun dalam kerangka teori. Hasil tersebut dapat dilihat pada tabel 3 Tabel 4.

Tabel 3

Model Struktural menggunakanVariabel Mediator

\begin{tabular}{|c|c|c|c|c|}
\hline Path & Estimate & C.R & P-Value & Kesimpulan \\
\hline $\begin{array}{l}\text { Motivasi Belajar <-Growth } \\
\text { Mindset }\end{array}$ & 0.470 & 9.941 & 0.000 & Signifikan \\
\hline $\begin{array}{l}\text { Motivasi Belajar < } \\
\text { Authoritative }\end{array}$ & 0.895 & 1.033 & 0.302 & Tidak Signifikan \\
\hline $\begin{array}{l}\text { Motivasi Belajar < } \\
\text { Permissive }\end{array}$ & 0.722 & 0.658 & 0.510 & Tidak Signifikan \\
\hline $\begin{array}{l}\text { Academic Grit }< \\
\text { Belajar }\end{array}$ & 1.509 & 7.183 & 0.000 & SIgnifikan \\
\hline
\end{tabular}


Keterangan tabel 3, estimasi bobot regresi dengan adanya mediator ditemukan hasil uji model struktural. Berikut adalah rincian hasil uji model struktural dengan empat keterangan.

1. Growth mindset memiliki pengaruh yang signifikan terhadap motivasi belajar. Hasil dari pengolahan menunjukkan nilai C.R. (Critical Ratio) sebesar $9.941 \mathrm{t}$-tabel $<1.96$ dengan nilai $\mathrm{P}<0.05$, artinya terdapat pengaruh yang signifikan growth mindset terhadap motivasi belajar. Kemudian untuk hasil koefisien estimasi sebesar 0.470. Hal ini menunjukkan adanya pengaruh positif, sehingga semakin tinggi growth mindset maka akan semakin tinggi motivasi belajar dan sebaliknya.

2. Pola asuh authoritative jika dibandingkan authoritarian sebagai kontrol tidak memiliki pengaruh yang signifikan terhadap motivasi belajar. Hasil dari pengolahan menunjukkan nilai C.R. (Critical Ratio) sebesar $-1.033<$ t-table 1.96 dengan nilai P $>0.05$, artinya tidak terdapat pengaruh yang signifikan dari pola asuh authoritarian terhadap motivasi belajar.

3. Pola asuh permissive jika dibandingkan authoritarian sebagai kontrol tidak memiliki pengaruh yang signifikan terhadap motivasi belajar. Hasil dari pengolahan menunjukkan nilai C.R. (Critical Ratio) sebesar $0.658<$ t-table 1.96 dengan nilai $\mathrm{P}<$ 0.05 , artinya tidak terdapat pengaruh yang signifikan dari pola asuh permissive terhadap motivasi belajar.

4. Motivasi belajar memiliki pengaruh yang signifikan terhadap academic grit. Hasil dari pengolahan menunjukkan nilai C.R. (Critical Ratio) sebesar $7.183>$ t-table 1.96 dengan nilai $\mathrm{P}<0.05$, artinya terdapat pengaruh yang signifikan dari motivasi

\section{Kesimpulan}

Berdasarkan hasil penelitian yang dilakukan pada siswa-siswi SMP Islamiyah Ciputat dengan keseluruhan sampel berjumlah 267 siswa dengan analisis menggunakan Structural Equation Modeling (SEM), maka dapat diperoleh model struktural dengan kesimpulan bahwa model dalam penelitian ini dikatakan model yang fit. Growth mindset secara signifikan mempengarahui academic grit. Parenting style tidak secara signifikan mempengaruhi academic grit. Sedangkan variabel motivasi belajar secara signifikan memediasi pengaruh growth mindset dan parenting style terhadap academic grit. 


\section{BIBLIOGRAFI}

Barrington, M. M. (2017). Assessing the link between grit and academic achievement in reading, mathematics, and writing among 4th graders: An explanatory sequential mixed methods inquiry. Texas A\&M University-Corpus Christi. Correspondence. Google Scholar

Barron, K. E., Hulleman, C. S., Getty, S., \& Taylor, J. A. (2017). Expectancy-ValueCost Survey of Student Motivation: User's Guide. Charlottesville, VA: The Motivate Lab. Google Scholar

Baumrind, D. (1991). Effective parenting during the early adolescent transition. Family Transitions, 2(1), 1. Google Scholar

Borghans, L., Duckworth, A. L., Heckman, J. J., \& Ter Weel, B. (2008). The economics and psychology of personality traits. Journal of Human Resources, 43(4), 9721059. Google Scholar

Bowen, R. P. (2018). The Relationship between Grit and Remedial Math Success for Black Males. Grand Canyon University. Google Scholar

Brian, K. (2015). OECD insights income inequality the gap between rich and poor: The gap between rich and poor. oecd Publishing. Google Scholar

Çelik, İ., \& Sariçam, H. (2018). The Relationships between Positive Thinking Skills, Academic Locus of Control and Grit in Adolescents. Universal Journal of Educational Research, 6(3), 392-398. Google Scholar

Chrisantiana, T. G., \& Sembiring, T. (2017). Pengaruh growth dan fixed mindset terhadap grit pada mahasiswa fakultas psikologi universitas " $X$ " Bandung. Humanitas (Jurnal Psikologi), 1(2), 133-146. Google Scholar

Clark, K. N., \& Malecki, C. K. (2019). Academic Grit Scale: Psychometric properties and associations with achievement and life satisfaction. Journal of School Psychology, 72, 49-66. Google Scholar

Coates, M. C. (2017). Integrating factors of grit in school culture: Case studies of two freshman academies. Oklahoma State University. Google Scholar

Collaco, C. M. (2018). What do we really know about grit? A multivariate statistical investigation on the construct validity of grit. Google Scholar

Cross, T. M. (2014). The gritty: grit and non-traditional doctoral student success. Journal of Educators Online, 11(3), n3. Google Scholar

Dent, R. J., \& Cameron, R. J. S. (2003). Developing resilience in children who are in public care: the educational psychology perspective. Educational Psychology in Practice, 19(1), 3-19. Google Scholar 
Peran Motivasi Belajar sebagai variabel mediator growth mindset dan parenting style

Deriana, R. (2019). Pemberitaan Ratna Sarumpaet Dalam Kasus Hoax (Analisis Framing Model Robert N. Entman Mengenai Pemberitaan Ratna Sarumpaet dalam kasus Hoax di media Online Pikiran-rakyat. com dan Jabar. tribunnews. com Edisi 2 Oktober 2018). Universitas Komputer Indonesia. Correspondence. Google Scholar

Duckworth, A. (2016). Grit: The power of passion and perseverance (Vol. 234). Scribner New York, NY. Google Scholar

Duckworth, A. L. (2006). Intelligence is not enough: Non-IQ predictors of achievement. University of Pennsylvania. Google Scholar

Dunn, K. (2017). Creating and Piloting an Instrument to Measure the Relationship between Parenting Style and College Student Grit. Google Scholar

Erawati, S. (2011). Pemberitaan Media Cetak Mengenai Kongres III PDIP di Bali (Studi Tentang Kecenderungan Narasi Pemberitaan Kongres III PDIP 2010 di Surat Kabar Nasional Kompas, Republika, dan Media Indonesia).Universitas Sebelas Maret Surakarta. Correspondence. Google Scholar

Gibbs, S., \& Miller, A. (2014). Teachers' resilience and well-being: A role for educational psychology. Teachers and Teaching, 20(5), 609-621. Google Scholar

Green, F. (2011). What is Skill?: An Inter-Disciplinary Synthesis. Francis Green. Citeseer. Google Scholar

Haktanir, A., Lenz, A. S., Can, N., \& Watson, J. C. (2016). Development and evaluation of Turkish language versions of three positive psychology assessments. International Journal for the Advancement of Counselling, 38(4), 286-297. Google Scholar

Haryanto, B., Ruldeviyani, Y., Rohman, F., TN, J. D., Magdalena, R., \& Muhamad, Y. F. (2019). Facebook analysis of community sentiment on 2019 Indonesian presidential candidates from Facebook opinion data. Procedia Computer Science, 161, 715-722. Google Scholar

Hibel, L. C., Granger, D. A., Cicchetti, D., \& Rogosch, F. (2007). Salivary biomarker levels and diurnal variation: Associations with medications prescribed to control children's problem behavior. Child Development, 78(3), 927-937. Google Scholar

Howard, J. M., Nicholson, B. C., \& Chesnut, S. R. (2019). Relationships between positive parenting, overparenting, grit, and academic success. Journal of College Student Development, 60(2), 189-202. Google Scholar

Husna, A., \& Satria, I. (2019). Effects of return on asset, debt to asset ratio, current ratio, firm size, and dividend payout ratio on firm value. International Journal of Economics and Financial Issues, 9(5), 50. Google Scholar 
Kemendikbud, S. J. (2016). Kementerian Pendidikan dan Kebudayaan. Direktorat Jenderal Pendidikan Dasar Dan Menengah, Direktorat Pembinaan Sekolah Dasar. Google Scholar

Levy, J. M., \& Steele, H. (2011). Attachment and grit: Exploring possible contributions of attachment styles (from past and present life) to the adult personality construct of grit. Journal of Social and Psychological Sciences, 4(2), 16-49. Google Scholar

Luthar, S. S., Doernberger, C. H., \& Zigler, E. (1993). Resilience is not a unidimensional construct: Insights from a prospective study of inner-city adolescents. Development and Psychopathology, 5(4), 703-717. Google Scholar

Maddi, S. R. (2006). Building an integrated positive psychology. The Journal of Positive Psychology, 1(4), 226-229. Google Scholar

Maddi, S. R., Matthews, M. D., Kelly, D. R., Villarreal, B. J., Gundersen, K. K., \& Savino, S. C. (2017). The continuing role of hardiness and grit on performance and retention in West Point cadets. Military Psychology, 29(5), 355-358. Google Scholar

McClelland, D. C. (1961). The achieving society: 210-215. D. Van Nostrand Co., New York. Google Scholar

Mitchum, J. E. (2018). Grit and Academic Growth for Third Graders: Is There a Relationship? Regent University. Google Scholar

Nuraini, Y., \& Aqila, M. (2020). Jagung Ketan (Zea mays ceratina) Role of Trichocompost and NPK 16-16-16 Fertilizer on N and P. Jurnal Tanah Dan Sumberdaya Lahan Vol, 7(1), 93-100. Google Scholar

Pierre, G., Sanchez Puerta, M. L., Valerio, A., \& Rajadel, T. (2014). STEP skills measurement surveys: innovative tools for assessing skills. Google Scholar

Pintrich, P. R., \& De Groot, E. V. (1990). Motivational and self-regulated learning components of classroom academic performance. Journal of Educational Psychology, 82(1), 33. Google Scholar

Putri, A. C. (2015). Pengembangan Media Pembelajaran Fisika Berbasis Web Untuk Meningkatkan Adversity Quotient Peserta Didik. Prosiding Seminar Nasional Fisika (E-Journal), 4, SNF2015-II. Google Scholar

Reed, L., \& Jeremiah, J. (2017). Student grit as an important ingredient for academic and personal success. Developments in Business Simulation and Experiential Learning: Proceedings of the Annual ABSEL Conference, 44. Google Scholar

Reraki, M., Celik, I., \& Saricam, H. (2015). Grit as a mediator of the relationship between motivation and academic achievement. Ozean Journal of Social Science, 
8(1), 19-32. Google Scholar

Riley, N., Lubans, D., Holmes, K., Hansen, V., Gore, J., \& Morgan, P. (2017). Movement-based mathematics: enjoyment and engagement without compromising learning through the EASY minds program. Eurasia Journal of Mathematics, Science and Technology Education, 13(6), 1653-1673. Google Scholar

Rojas, J. P. (2015). The relationships among creativity, grit, academic motivation, and academic success in college students. Google Scholar

Stauffer, M. B. (2018). Mindset, Grit, and Family Influence as Factors in Postsecondary Goals. Delaware Valley University. Google Scholar

Stoltz, P. G. (2005). Adversity Quotient Mengubah Hambatan Menjadi Peluang, cet ke6. PT Gramedia. Google Scholar

Suzuki, Y. (2015). Tamesue., D., Asahi, K., \& Ishikawa, Y.(2015). Grit and Work Engagement: A Cross-Sectional Study. PLoS ONE, 10(9). Google Scholar

Toland, J. (2011). és Carrigan, D. Educational Psychology and Resilience: New Concept, New Opportunities, School Psychology International, 32, 95-106. Google Scholar

Vallerand, R. J., Pelletier, L. G., Blais, M. R., Briere, N. M., Senecal, C., \& Vallieres, E. F. (1992). The Academic Motivation Scale: A measure of intrinsic, extrinsic, and amotivation in education. Educational and Psychological Measurement, 52(4), 1003-1017. Google Scholar

Von Culin, K. R., Tsukayama, E., \& Duckworth, A. L. (2014). Unpacking grit: Motivational correlates of perseverance and passion for long-term goals. The Journal of Positive Psychology, 9(4), 306-312. Google Scholar

Wahidah, F. R., \& Royanto, L. R. M. (2019). Peran kegigihan dalam hubungan growth mindset dan school well-being siswa sekolah menengah. Jurnal Psikologi TALENTA, 4(2), 133-144. Google Scholar

Weisskirch, R. S. (2018). Grit, self-esteem, learning strategies and attitudes and estimated and achieved course grades among college students. Current Psychology, 37(1), 21-27. Google Scholar

Wigfield, A., \& Eccles, J. S. (2000). Expectancy-value theory of achievement motivation. Contemporary Educational Psychology, 25(1), 68-81. Google Scholar

Zhao, X., Deng, S., \& Zhou, Y. (2017). The impact of reference effects on online purchase intention of agricultural products: The moderating role of consumers' food safety consciousness. Internet Research. Google Scholar

Zhou, K. (2016). Non-cognitive skills: definitions, measurement and malleability. Paper 
Faatihatul Ghaybiyyah

commissionedfor the Global Education Monitoring Report 2016. Education for People and Planet: Creating Sustainable Futures for All.

\section{Copyright holder:}

Faatihatul Ghaybiyyah (2021)

\section{First publication right:}

Syntax Idea

This article is licensed under:

(c) (i) (O) 